\title{
La parotidite asymptomatique de carence
}

L'appareil digestif commence aux lèvres... vérité trop méconnue de nombreux gastroentérologues, qui attribuent la cavité buccale, le pharynx et l'cesophage supérieur à d'autres spécialistes, et ne s'intéressent qu'à la partie sous-diaphragmatique de cet appareil. Ainsi le role des dents est minimise, la langue inspectée sommaire-ment mais non étudiée, la salive negligee; pourtant cette secretion occupe sa place dans l'ensemble des phénomènes de digestion, et les glandes qui la produisent possèdent même, en plus, une fonction endocrine; ce n'est pas par hasard que les Allemands appellent le pancreas: Bauchspeicheldrüse, «glande salivaire de Гabdomen»!

Le gonflement ou l'hypertrophie parotidienne est par ailleurs un symptôme décrit dans un certain nombre d'états pathologiques, le diabète notamment. On n'en a guère parlé à l'occasion des etudes consacrées aux affamés de la dernière guerre; mais pourtant R.Kanther, en Allemagne, avait observe des parotidites en tel nombre qu'il s'était demandé s'il ne s'agissait pas d'une épidémie d'oreillons (Z. ges. inn. Med.; no 3, p. 87, 1948); et Гapparition de cette hypertrophie chez des sujets particulièrement amaigris, parallèlement à des ædèmes de famine, permettait à $\mathrm{H}$. Gounelle (Soc. Méd. Hop. Paris, 27 juin 1952; in: Bull, et mém., v. 68, p. 866) d'affirmer la relation avec une «carence azotée elective». Elle existerait également dans la cirrhose alcoolique de façon quasi-constante (et curieusement méconnue!) d'après H. Bonnín, G. Morettí et A. Geyer (Presse mêdícale du 22 oct. 1954, p. 1449), Гaugmentation du volume des parotides apparaissant ici comme une «adaptation du tissu glandulaire à une exaltation de la fonction salivaire».

Un gros article recent signé par H. R. Sandstead et deux collabora-teurs (Amer. J. Clín. Nutrít.; vol. 3, p. 198, mai-juin 1955) vient de reprendre la question sur une base quasi-expérimentale, en com-parant les observations faites chez plus de 3000 Asiatiques à l'occasion d'une enquête sur la sous-alimentation en Extreme-Orient, avec les examens pratiques chez des sujets de toutes races dans des hôpitaux ou asiles américains. Chez ces derniers, on trouve $12 \%$ de parotidites chez les Indiens, contre 3,5 \% chez les Américains d'autre origine; quant aux indigenes d'ExtrêmeOrient, on trouve la parotidite dans

Editorial

367

$12 \%$ des poids normaux, $16 \%$ des amaigrissements modérés, $33 \%$ des pertes de poids sévères. La parotidite n'est d'ailleurs pas un symptôme isolé: elle coincide presque toujours avec une pigmentation pellagroïde des mains et de la face, des rhagades commissurales labiale, de Tanémie et de I'hypoprotidémie; en revanche, on n'a pas note de carence en vitamines A et C dans le sang.

La parotidite se développe lentement, mais progressivement: des sujets jusque-là à la limite inférieure de la nutrition rationnelle, puis carencés, voient Thypertrophie se manifester en 2 à 4 mois, atteindre son maximum en 6 à 8 mois, persister ensuite selon les circonstances alimentaires, et même parfois après la reprise d'une nourriture convenable, représentant alors un 
témoin d'une période antérieure de famine; cependant, des individus bien nourris résistent pendant 4 à 6 mois aux privations, sans voir leur parotide gonfler.

Des cultures du tissu glandulaire prélevé par ponction ont permis de

prouver $\Gamma$ absence de virus, et $\Gamma$ examen histologique révèle des aspects

non-inflammatoires; il existe d'abord un gonflement de chaque

cellule, puis le tissu des acini est partiellement remplacé par de la

graisse. Enfin, la secretion salivaire n'est pas déficiente, même après

une longue période de parotidite. M. D.

Referate - Abstracts - Analyses

Bearbeitet von: - Edité par:

M. Demole, Geneve; H. Jenzer, Bern; H. Kapp, Basel; N. Lloreti Barcelona;

L. Norpoth, Essen; B. Wíssmer, Geneve

VIII. Gallenwege - Voies biliaires

1. Diagnostik

Wieser, C: Nouvelle méthode de volumetric au cours de l'épreuve d'évacuation en

cholécystographie. Schweiz. med. Wschr. 84, 149-153, 1954. Es sind sehr viele Vorschläge gemacht worden, die darauf hinzielen, die klassische Cholécystographie mit Fettmahlzeit zu verbessern und damit bessere klinische Re-sultate herauszuholen. Die Methodik des Yerfassers besteht in je einer Profil- und a-p-Aufnahme einer mit Kontrastmittel gefüllten Gallenblase vor und nach Fettmahlzeit in Rückenlage. Vorher wird am Schirm die genaue Projektion der Gallenblase auf der Haut angezeichnet und der Zentralstrahl wird dann auf die Mitte ge-richtet. Wenn die beiden Flächeninhalte bekannt sind, gelingt es mit einer relativ einfachen Formel, auf das Volumen zu schließen. Am Modellversuch konnte festge-stellt werden, daß die Formel genügend genaue Resultate ergibt. Nur wenn die Gallenblase sehr unregelmäßig konturiert ist, versagt die Methode. Selbstverständ- 